See Article page e275.

\section{Commentary: "When I was in training"- The phrase we hate to hear, but love to say}

\author{
Charles B. Huddleston, MD, and
}

Andrew C. Fiore, MD

"When I was in training," reoperations after repair of tetralogy of Fallot (TOF) were very unusual. In 1993, The New England Journal of Medicine published a landmark article regarding the long-term outcome of patients undergoing repair of TOF at the Mayo Clinic from 1955 to 1960, with a $98 \%$ follow-up for an average of longer than 20 years. ${ }^{1}$ As one might expect, the operative mortality from that era was very high-20\%. For those patients surviving the operation, the 30-year actuarial survival was $86 \%$, and the 30 year freedom from reoperation was $88 \%$. $^{1}$ These are outstanding long-term results with a surprisingly low reoperation rate. We are not going to pretend that the patients undergoing repair of TOF from 1955 to 1960 are in any way similar to those patients undergoing repair of TOF in 2019 — they are not—but these data (and our fond recollection of our training experience) provide a reasonable lens through which we can view the current era of published results of repair of TOF as we continue to endeavor to strive to provide normal life expectancy for these patients.

"When I was in training," the focus was on relief of the right ventricular outflow tract (RVOT) obstruction, without a lot of concern regarding the consequences of pulmonary valve insufficiency, with the proviso that a little pulmonary stenosis was not a bad thing. The recognition that pulmonary valve insufficiency has deleterious long-term effects on at least the right ventricle has shifted the focus of most investigations of TOF repair during the past 10 years to valve- or annulus-sparing techniques. The relatively small pulmonary valve in TOF would naturally result in some RVOT obstruction. In this issue of the Journal, Tan and colleagues $^{2}$ from Melbourne investigate the implications of

\footnotetext{
From the Department of Surgery, Saint Louis University School of Medicine, St Louis, Mo.

Disclosures: Authors have nothing to disclose with regard to commercial support.

Received for publication Oct 17, 2019; revisions received Oct 17, 2019; accepted for publication Oct 18, 2019; available ahead of print Jan 7, 2020.

Address for reprints: Charles B. Huddleston, MD, Department of Surgery, Saint Louis

University School of Medicine, 1465 S Grand Blvd, St Louis, MO 63104 (E-mail:

Charles.huddleston@health.slu.edu).

J Thorac Cardiovasc Surg 2020;159:e279-80

$0022-5223 / \$ 36.00$

Copyright (c) 2019 by The American Association for Thoracic Surgery

https://doi.org/10.1016/j.jtcvs.2019.10.091
}

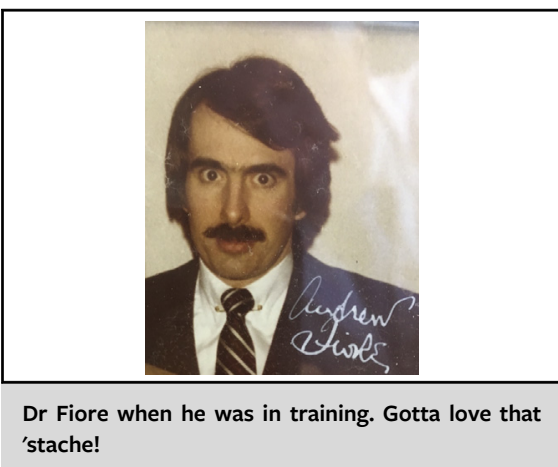

CENTRAL MESSAGE

Techniques for repair of tetralogy of Fallot that preserve the pulmonary valve inevitably result in residual right ventricular outflow tract obstruction. The long-term effects of this are unknown.

leaving a gradient in the RVOT while preserving pulmonary valve competency (presumably). Approximately one-third of all their patients (126/342) either had a gradient of greater than $36 \mathrm{~mm} \mathrm{Hg}$ develop or had it when the operation was completed; the vast majority had the gradient essentially on completion of the repair. Of the 126 patients with residual or recurrent gradients, 50 required reoperation, for an incidence of $40 \%$; the reoperation incidence in the remaining 216 patients is not reported. If we are to assume that none of the 216 other patients required reoperation during the median follow-up period of 8 years, the incidence of reoperation of the entire group was around $15 \%$ (50/342). Some patients with relatively high gradients early on subsequently had a reduction in the gradient with time and did not require reoperation. Tan and colleagues ${ }^{2}$ recommend that at least 2 serial studies be performed before subjecting patients to reoperation for residual RVOT gradients.

"When I was in training," leaving a gradient of more than $30 \mathrm{~mm} \mathrm{Hg}$ across the RVOT would not be acceptable. The impact of pulmonary valve insufficiency has been the focus of most studies on TOF during the past decade-over 250 publications, in fact. Without question, efforts to avoid this are appropriate. The issue to us is the effects of right ventricular hypertrophy (and early reoperations) or right ventricular dilatation (and 
late reoperations) during the long term. A reoperation rate of $15 \%$ during an 8 -year follow-up seems unreasonable. Although Tan and colleagues ${ }^{2}$ conclude that some patients with high gradients avoid reoperation as a result of an unpredictable natural reduction in the gradient, this provides little solace.

\section{References}

1. Murphy JG, Gersh BJ, Mair DD, Fuster V, McGoon MD, Ilstrup DM, et al. Longterm outcome in patients undergoing surgical repair of tetralogy of Fallot. $N$ Engl J Med. 1993;329:593-9.

2. Tan C, Soquet J, Brizard CP, d'Udekem Y. Evolution of residual and recurrent right ventricular outflow tract obstruction after tetralogy of Fallot repair. J Thorac Cardiovasc Surg. 2020;159:e275-7. 